\title{
Ekonomik Büyüme ve Finansal Kalkınma Seviyesine Göre Belirsizliğin Etkisi: Türkiye Örneği
}

\author{
DOI: 10.26466/opus.780239
}

$*$

\author{
Ecenur Uğurlu Yıldırım * \\ * Dr. Öğretim Üyesi, Ankara Sosyal Bilimler Üniversitesi \\ E-Posta: ecenur.yildirim@asbu.edu.tr \\ ORCID: $\underline{0000-0001-6465-4781}$

\section{Öz}

Finansal kalkınma düzeyi ve ekonomik büyüme arasındaki ilişki, uzun yıllardır tartışmaların odağı halindedir. Ülke belirsizliğin makroekonomik değişkenler üzerindeki etkisi ise son yılların ilgi gören konularının başında gelmektedir. Bu çalı̧̧mada Türkiye örneklemi kullanılarak, finansal kalkınma ve ekonomik büyüme düzeyine göre ülke belirsizliğinin etksi ampirik olarak incelenmiştir. Ocak 1998- Aralık 2019 zaman aralı̆̆ındaki dönem için çeyreklerden oluşan zaman serisi verileri kullanılmıştır. Gecikmesi dağıtılmış otoregresif modelden ( $A R D L$ ) faydalanılarak, ilgili değgişkenlerin uzun ve kısa dönem etkileri araştırılmıştır. Sonuçlarımıza göre kısa vadede, belirsizliğin ekonomik büyüme üzerindeki olumsuz etkileri, finansal kalkınma düzeyi arttıkça azalmaktadır. Öte yandan, ekonomik büyümenin düzeyi, belirsizliğin finansal kalkınmaya etkisi üzerinde her hangi bir değişikliğe neden olmamaktadır. Son olarak, Türkiye uzun vadede talep-takibi davranışı gösterirken, kısa vadede arz-liderliği davranışı sergilemektedir. Bu bulgu, Türkiye'nin finansal sisteminin uzun vadede üretken yatırımlar belirlemekte ve fonlamakta sorun yaşadığı şeklinde yorumlanabilir. Makalemizin sonuçları, finansal sektörün gelişmişliğinin ve kalitesinin, belirsizliğin olumsuz etkilerini azaltmadaki rolünü göstererek, politika yapıcılara önemli bilgiler să̆lamaktadır.

Anahtar Kelimeler: belirsizlik, finansal kalkınma, ekonomik büyüme, ARDL 


\title{
Impact of Uncertainty Depending on the Economic Growth and Financial Development Level: The Case of Turkey
}

\begin{abstract}
The relationship between financial development and economic growth has been the focus of discussions for many years. On the other hand, the impact of country uncertainty on macroeconomic variables is one of the most popular topics of recent years. The purpose of this study is to empirically examine whether the impact of uncertainty on economic growth and financial development is changed according to the level of financial and economic development. As a sample quarterly time series data between January 1998 and December 2019 for Turkey were employed. Using the Autoregressive Distributed Lag (ARDL) model, the long and short-term effects of the relevant variables were investigated. According to our results, the adverse effects of uncertainty on economic growth decrease in the short-run as the level of financial development increases. On the other hand, the level of economic growth does not cause any changes on the impact of uncertainty on financial development. Finally, Turkey shows demand-following behavior in the long term, while exhibiting supply-leading behavior in the short term. This finding can be interpreted as Turkey's financial system faces problems to determine the productive investments and funding them in the long-run. The results of our article provide valuable insight to policymakers by showing the role of the development and quality of the financial sector in reducing the negative effects of uncertainty.
\end{abstract}

Keywords: uncertainty, financial development, economic growth, ARDL 


\section{Giriş}

Ekonomik büyüme ve finansal kalkınma arasındaki ilişki uzun süredir tartışmaların odağında olan bir konudur. Ülke belirsizliğinin, makroekonomik göstergeler üzerindeki etkisi de son yıllarda ilgi gören bir başka konu haline gelmiştir. Çalışmamızda, Türkiye için ekonomik büyüme ve finansal kalkınma seviyesinin, ülke belirsizliğinin etkisi üzerinde fark yaratıp yaratmadığı ampirik olarak incelenerek, bu iki literatür arasındaki bağlantıya katkıda bulunmak hedeflenmiştir.

Örneklem olarak Türkiye'deki Ocak 1998- Aralık 2019 yılları arasndaki çeyrek dönem zaman serileri kullanılmış olup, gayrisafi yurtiçi hasıla büyümesi, özel sektöre verilen kerdilerin gayrisafi yurtiçi hasıladaki oranı ve Ahir, Bloom, ve Furceri (2018) tarafından hazırlanan ülkelere göre dünya belirsizlik endeksi verileri incelenmiştir. Sınır testi yaklaşımı ile değişkenler arasındaki uzun dönem eşbütünleşmenin varlı̆̆ belirlendikten sonra, gecikmesi dağıtılmış otoregresif model (ARDL) yöntemiyle ilgili değişkenlerin uzun ve kısa dönem etkileşimleri araştırılmıştır.

Makalemizin belirtilen literatürlere katkısı iki ana başlık altında toplanabilir. İlk olarak, belirsizliğin ekonomik büyüme ve finansal kalkınma üzerindeki etkisinin, ekonomik büyüklük ve finansal kalkınmışlık seviyesiyle değişip değişmediğini Türkiye için ampirik olarak gösteren ilk çalışmadır. Bulgularımız, kısa dönem için belirsiziğin ekonomik büyüme üzerindeki negatif etkisinin, finansal kalkınma arttıça düştüğünü göstermektedir. Literatüre sağladığımız bir diğer katkı ise, Türkiye' deki belirsizliğin finansal kalkınma üzerindeki uzun dönem ve kısa dönem etkilerini ARDL yöntemi ile sunmaktır. Sonuçlarımıza göre ülke belirsizliğinin finansal kalkınma üzerinde ne uzun ne de kısa dönemde bir etkisi bulunmamaktadır.

Yukarıda da belirtildiği üzere makelemiz iki ana literatürü ilgilendirmektedir. Bunlardan ilki, ekonomik büyüme ve finansal gelişme arasındaki ilişkiyi inceleyen araştırmalardır. Pek çok ekonomist, finansal kalkınmanın ekonomik büyüme üzerinde hiçbir etkisi olmadığını ileri sürse de, son ampirik bulgular, iki değişken arasında pozitif ve çift yönlü bir ilişkinin varlığını gözler önüne sermiştir. Robinson (1952) ve Lucas (1988) gibi bazı ekonomistler finansal sistemin etkisinin abartıldı̆̆ını ve ekonomik büyümeye pasif olarak tepki verdiğini iddia ederken, Schumpeter (1912) gibi araştırmacılar, finansal sistemin üretken yatırımları belirleyerek ve fonlayarak ekonomik büyümeye 
önemli etkileri olduğunu belirtmiştir. Patrick (1966) ise bu tartışmaya, "arzliderliği ve talep-takibi (supply-leading and demand following)" hipoteziyle katkıda bulunmuştur. Bu hipoteze göre, arz-liderliği davranışı, yeni finansal kuruluşlar ve pazarlar yaratmasından ötürü finansal kalkınmadan ekonomik büyümeye doğru bir nedensellik ifade ederken, talep-takibi, ekonomik büyümden finansal kalkınmaya doğru bir nedensellik olduğunu belirtmektedir. Patrick (1966)'ya göre, kalkınmanın erken dönemlerinde arz-liderliği davranışı gözlemlenirken, ülke ekonomik ve finansal olarak geliştikçe taleptakibi davranışı arz-liderliği davranışını domine etmektedir. King ve Levine (1993a, b), finansal gelişmenin ekonomik büyüme üzerinde ampirik olarak güçlü ve pozitif etkiye sahip olduğuna dair kanıtlar sunan ampirik makaleler dizisiyle mevcut literatürü bir adım öteye taşımaktadır. Teorik modeller, finansal gelişmenin ekonomik büyümeyi iki yolla etkilediğini göstermektedir. Her şeyden önce finansal kalkınmanın tasarruf oranını yükselterek ekonomik büyümeyi arttırdığı ve bunun da mevcut yatırım kaynaklarında bir artışa yol açtığ ifade edilmektedir. McKinnon (1973) ve Shaw (1973), finansal kurumların bilgi asimetrisini azalttıkça, tasarrufları mobilize etme maliyetini düşürdüklerini ve bunun da daha yüksek tasarruf oranlarına ve dolayısıyla daha fazla yatırım ve ekonomik büyümeye neden olduğunu iddia ederek bu görüşü desteklemektedir. İkinci görüşe göre ise, finansal gelişme tasarrufları daha verimli bir şekilde tahsis ederek, diğer bir deyişle yatırımın verimliliğini artırarak ekonomik büyümeyi arttırmaktadır.

Çalışmamızın ilgili olduğu ikinci araştırma grubu ise, belirsizliğin makroekonomik göstergeler üzerindeki etkisini konu alan literatürdür. Bir yandan bazı çalışmalar siyasi belirsizliğin, hükümeti kamu yatırımlarına yapılan harcamaları artırmasına neden olan özel yatırımı azalttığı için ekonomik büyümeyi artırdığını öne sürmektedir (Bui, 2018). Öte yandan, geniş bir literatür, siyasi istikrarsılı̆̆ın, yatırımları ve tasarrufları olumsuz yönde etkileyerek ekonomik büyümeyi olumsuz etkilediğini göstermektedir (Barro, 1991, s. 408; Mauro, 1995, s. 681; Alesina ve Perotti, 1996, s.1205; Jong-a-Pin, 2009, s. 15). Yapılan pek çok araştırmada, belirsizliğin yatırım ve ekonomik büyüme üzerindeki olumsuz etkileri gözler önüne serilmiştir (bkz. Lensink, 2001, s. 300; Aizenman ve Marion, 1993, s. 207). Yüksek belirsizliğin, olumlu ve olumsuz durumlardaki sonuçları asimetrik olarak etkilediği, talebin beklenmedik şekilde yüksek olduğu zamanlarda firma sermaye stoğunu kolayca arttırabilirken, aksi durumda yatırım kararını geri alamadığından dolayı etkisinin 
daha büyük olduğu savunulmuştur (Dixit ve Pindyck, 1994; Lensink, 2001). Çalışmalar belirsizliğin aynı zamanda banka kredileri üzerinde de etkisi olduğunu göstermiştir. Ekonomik politika belirsizliğinin ekonomi üzerindeki etkisinin banka kredi kanalı aracılığıyla meydana geldiğini savunan bu araştırmalar, yüksek ekonomik politika belirsizliğinin banka kredilerini azaltarak ekonomik büyümeyi yavaşlattığını ileri sürmektedir (Gözgör vd., 2019). Çağlayan ve Xu (2019), 18 ülkenin panel veri setini kullanarak, ekonomik politika belirsizliğinin kredi seviyesi, takipteki krediler ve kredi zararı karşılıkları üzerindeki etkisini incelemiş ve belirsizliğin artmasının kredinin kullanılabilirliğini azalttığını ve bankaların takipteki kredilerini ve kredi zararı karşılıklarını artırdığını bulmuşlardır. Çin bankalarını inceleyen Chi ve Li (2017) de benzer şekilde ekonomik politika belirsizliğinin banka kredi riskini arttırırken kredi büyüklüğünü azalttığı sonucuna varmıştır. Gözgör vd. (2019) ise bu literatüre, Ahir vd.'nin (2018) oluşturduğu dünya belirsizlik endeksinin yurtiçi kredi seviyesi üzerindeki etkisini 139 ülkenin panel veri kümesini kullanarak araştırdığı çalışmasıyla katkıda bulunmuştur. Sonuçları, yüksek belirsizlik seviyesinin yurtiçi kredi seviyesini düşürdüğü yönündedir.

Finansal piyasa gelişimi ve ekonomik büyüme ile ilgili literatür, gelişmiş bir finansal sistemin riskleri daha etkili bir şekilde yönetebilmesinden ötürü, belirsizliğin ekonomik büyüme üzerindeki etkisinin bir ülkenin finansal sektörünün gelişimine bağlı olduğunu ileri sürmektedir. Karaman ve Karaman (2019), 1971 ve 2009 yılları arasında 50 ülkeden oluşan üç aylık periyotlardan oluşan panel veri setini kullanarak enstrümantal değişkenler modeliyle finansal gelişmenin belirsizliğin ekonomik çıtı üzerindeki olumsuz etkisini azaltıp azaltmadığını araştırmıştır. Ampirik bulguları, finansal gelişmenin belirsizliğin ekonomik çıktı üzerindeki olumsuz etkisini azalttığına dair önemli kanıtlar sunmaktadır. Düşük finansal gelişme seviyelerinde, belirsizliğin çıktı üzerindeki etkisi negatif ve istatistiksel olarak anlamlıyken, yüksek finansal gelişme seviyelerinde, çıktı üzerindeki etkisi önemsizdir. Finansal gelişmişlik düzeyi daha yüksek olan ülkelerde, belirsizlik karşısında hem yatırım hem de tüketim sözleşmelerinin daha az daraldığı gözlemlenmiştir. Bu sonuç finansal kalkınmanın hafifletici etkisinin yatırım kanallarının yanı sıra tüketim kanalları üzerinden de işlediğini göstermektedir. Belirsizliğin ekonomik aktiviteyi finansal sürtünmeler yoluyla bastırdığı durumlarda, düşük finansal gelişmenin sürtünmeleri daha da kötüleştirerek olumsuz etkiyi arttıracağı vurgulanmıştır. Daha az gelişmiş bir finansal sektörün, firmaları ve 
hane halklarını etkileyen kredi kısıtlamalarının olasılığını arttıracağı ve bununla birlikte dış finansman maliyetinin artacağı belirtilmiştir. Belirsizliğin etkisi ihtiyati teşvikler yoluyla gerçekleştiği durumlarda ise, zayıf bir finansal sektörün ihtiyati teşvikleri şiddetlendireceği vurgulanmıştır. Finansal kalkınma düzeyinin düşük olması belirsizlik döneminde karlı projelerin ertlenemsine neden olurken, gelişmiş bir finans piyasası kaynakların zamanlararası yeniden tahsisi yoluyla tüketimin yumuşatılmasına izin vererek durgunluklardan kurtulmayı kolaylaştıracağı belirtilmişir (Karaman ve Karaman, 2019).

Finansal kalkınma ve belirsizlik arasındaki ilişkiyi inceleyen çok sayıda teorik çalışma olmakla birlikte, konuyla ilgili ampirik makale sayısı kısıtılıdır. Bu makale, politika belirsizliği ile finansal gelişme literatürünü birbirine bağlayarak literatürdeki bu boşluğu doldurmayı amaçlamaktadır. Çalışmamızın sonucunda, Türkiye için belirsizliğin uzun dönemde ekonomik büyümeye etkisi olmamakla birlikte, kısa dönemde belirsizliğin artmasının ekonomik büyümeyi azaltttğ gösterilmiştir. Ancak finansal kalkınmanın bu negatif etkiyi azalttığ1 gözlemlenmiştir. Diğer bir taraftan, belirsizliğin finansal kalkınma üzerinde anlamlı bir etkisi bulunmamıştır. Son olarak, Türkiye'nin 1998-2019 seneleri arasında uzun dönemde talep-takibi hiptezini desteklerken, kısa dönemde arz-liderliği davranışı sergilediği sonucuna ulaşılmıştır.

Makalemizin bundan sonraki bölümü yöntem ve örneklemden bahsederken, üçüncü bölümde ampirik bulgular ortaya konmaktadır. Son bölümde ise çalışmaya ait sonuçlar belirtilerek, politika yapıcıları ve yatırımcılar için öneriler sunulmaktadır.

\section{Yöntem}

Çalışmamızda, Pesaran ve Pesaran (1997) ve Pesaran, Shin ve Smith (2001) tarafından ortaya konulan gecikmesi dağıtılmış otoregresif model (ARDL) yaklaşımı kullanılmıştır. ARDL yaklaşımının diğer yaklaşımlara göre bazı avantajları vardır. İlk olarak, kullanılan seri durağan olmak zorunda değildir. Bu yaklaşım, I (0), I (1) olmalarına veya karışık olarak hem düzeyde hem de birinci derecede durağan olmalarına bakılmaksızın I(2)'den düşük bütün serilere uygulanabilmektedir (Pesaran ve Pesaran, 1997). İkincisi, küçük örneklemlerle bile, verimli eşbütünleşme ilişkileri belirlenebilmektedir (Ghatak ve Siddiki, 2001). Son olarak, durağan olmayan zaman serisi verilerinin sıfira 
doğru eğilimli sahte regresyon katsayılarına yol açtığı bilinmektedir (Stock and Watson, 2003). Laurenceson ve Chai (2003), ARDL'nin yaklaşımının durağan olmayan zaman serisi verilerinden kaynaklanan bu gibi problemlerin de üstesinden geldiğini bildirmektedir.

ARDL yöntemi üç adımdan oluşur. İlk adım, sınır testi yaklaşımı kullanılarak değişkenler arasında eşbütünleşmenin varlığının test edilmesidir (Pesaran ve Pesaran, 1997; Pesaran vd., 2001; Sari, Ewig, Soytas, 2008). Bu test, bağımlı değişken ile bağımsız değişkenlerin uzun dönem ilişkisini göstermektedir. Uzun dönemli ilişkinin varlığını test etmek için, aşağıda yer alan regresyon modelleri kullanılmıştır:

$$
\begin{aligned}
& \Delta G S Y \dot{\mathrm{I}} H B_{t}=\alpha_{0}+\sum_{i=1}^{n} b_{1} \Delta G S Y \dot{\mathrm{I}} H B_{t-i}+\sum_{i=0}^{n} b_{2} \Delta K R E D \dot{\mathrm{I}}_{t-i} \\
& +\sum_{i=0}^{n} b_{3} \Delta W U I_{t-i}+\sum_{i=0}^{n} b_{4} \Delta E N T F K_{t-i} \\
& +\sum_{i=0}^{n} b_{5} \Delta E N F L A S Y O N_{t-i}+\omega_{1} G_{S Y \dot{I} H} B_{t-1} \\
& +\omega_{2} K R E D \dot{\mathrm{I}}_{t-1}+\omega_{3} W U I_{t-1}+\omega_{4} \text { ENTFK }_{t-1} \\
& +\omega_{5} \text { ENFLASYON }_{t-1}+\varepsilon_{t} \\
& \Delta K R E D \dot{\mathrm{I}}_{t}=\alpha_{0}+\sum_{\substack{i=1 \\
n}}^{n} b_{1} \Delta K R E D \dot{\mathrm{I}}_{t-i}+\sum_{\substack{i=0 \\
n}}^{n} b_{2} \Delta G S Y \dot{\mathrm{I}} H B_{t-i} \\
& +\sum_{i=0}^{n} b_{3} \Delta W U I_{t-i}+\sum_{i=0}^{n} b_{4} \Delta E N T E B_{t-i} \\
& +\sum_{i=0}^{n} b_{5} \Delta E N F L A S Y O N_{t-i}+\omega_{1} K R E D \dot{\mathrm{I}}_{t-1} \\
& +\omega_{2} G S Y \dot{I} H B_{t-1}+\omega_{3} W U I_{t-1}+\omega_{4} E N T E B_{t-1} \\
& +\omega_{5} \text { ENFLASYON }_{t-1}+\varepsilon_{t}
\end{aligned}
$$

Yukarıdaki denklemlerde, GSYİHB, KREDİ, WUI, ENTFK, ENTEB ve ENFLASYON, sırasıyla ekonomik büyüme, finansal olmayan sektöre sağlanan toplam kredilerin gayrisafi yurtiçi hasılaya oranı, belirsizlik endeksi, finansal kalkınma için etkileşim terimi, ekonomik büyüme için etkileşim terimi 
ve enflasyonu belirtmektedir. b parametreleri kısa dönem katsayılarını gösterirken, $\omega$ sembolü uzun dönem çarpanını ifade etmektedir. Denklem 1 ve 2 için "eşbütünleşme yoktur" hipotezi $\left(\omega_{1}=\omega_{2}=\omega_{3}=\omega_{4}=\omega_{5}\right)$ test edilmiştir (Peseran ve Peseran, 1997; Peseran, 2001; Sari vd., 2008).

İkinci adımda, ilk adımda tanımlanan uzun dönemli ilişkilerin katsayıları tahmin edilmektedir. Bağımlı ve bağımsız değişkenler arasında uzun dönemli ilişkiler (yani eşbütünleşme) bulunduktan sonraki adımda uzun vadedeki ilişkinin katsayıları seçilmiş ARDL ( $\mathrm{f}, \mathrm{g}$, $\mathrm{h}, \mathrm{z}, \mathrm{r}$, ) modelleri kullanılarak tahmin edilmektedir.

$$
\begin{aligned}
& G S Y \dot{\mathrm{I}} H B_{t}=\alpha_{0}+\sum_{i=1}^{f} \beta_{i} G S Y \dot{\mathrm{I}} H B_{t-i}+\sum_{i=0}^{g} \gamma_{i} K R E D \dot{\mathrm{I}}_{t-i} \\
& +\sum_{i=0}^{h} \delta_{i} W U I_{t-i}+\sum_{i=0}^{z} \theta_{i} E N T F K_{t-i} \\
& +\sum_{i=0}^{r} \tau_{i} \text { ENFLASYON }_{t-i}+\varepsilon_{t} \\
& K R E D \dot{\mathrm{I}}_{t}=\alpha_{0}+\sum_{i=1}^{f} \beta_{i} K R E D \dot{\mathrm{I}}_{t-i}+\sum_{i=0}^{g} \gamma_{i} G S Y \dot{\mathrm{I}} H B_{t-i} \\
& +\sum_{i=0}^{h} \delta_{i} W U I_{t-i}+\sum_{i=0}^{z} \theta_{i} E N T E B_{t-i} \\
& +\sum_{i=0}^{r} \tau_{i} \text { ENFLASYON }_{t-i}+\varepsilon_{t}
\end{aligned}
$$

$\mathrm{f}, \mathrm{g}$, h, z, r gecikme uzunlukları literatüre dayanarak Schwartz Bayesian Kriteri kullanılarak belirlenmiştir (Peseran ve Peseran, 1997). Veri setimizi çeyrek periyotlar oluşturduğu için, bir seneye tekabül eden maksimum 4 gecikme kullanılmıştır. 
Son olarak üçüncü adımda kısa dönem dinamikleri belirlemek amacıyla ARDL hata düzeltme modeli test edilerek kısa dönem katsayıları tahmin edilmiştir (Sari vd., 2008). Hata düzeltme teriminin katsayısı (ECT), uzun dönemde, kısa dönemde oluşan bir dengesizliğin düzelme miktarını ifade etmektedir. Bu sayının istatistiksel olarak anlamlı ve negatif olması istenmektedir (Akel ve Gazel, 2014).

Tablo 1. Tanımlayıcı istatistikler

\begin{tabular}{lllll}
\hline & GSYİHB & KREDI & WUI & ENFLASYON \\
\hline Ortalama & 4.544 & 18.760 & 39.723 & 21.846 \\
\hline Medyan & 5.915 & 18.626 & 1.451 & 9.557 \\
\hline Maksimum & 11.899 & 35.087 & 766.681 & 99.274 \\
\hline Minimum & -12.526 & 7.069 & -87.260 & 4.344 \\
\hline Standard Sapma & 5.299 & 9.243 & 136.695 & 23.564 \\
\hline $\mathrm{N}$ & 84 & 88 & 87 & 88 \\
\hline
\end{tabular}

Not: Tablo 1'de kullanılan değişkenlerin tanımlayıcı istatistikleri sunulmuştur. GSYİHB, KREDİ, WUI, ENFLASYON sırasıyla gayrisafi yurtiçi hasıladaki büyüme, finansal olmayan özel sektöre sağlanan kredilerin toplamının gayrisafi yurtiçi hasılaya oranı, belirsizlik endeksi değişimi, ve enflasyonu belirtmektedir. $\mathrm{N}$ ise gözlem sayısıdır.

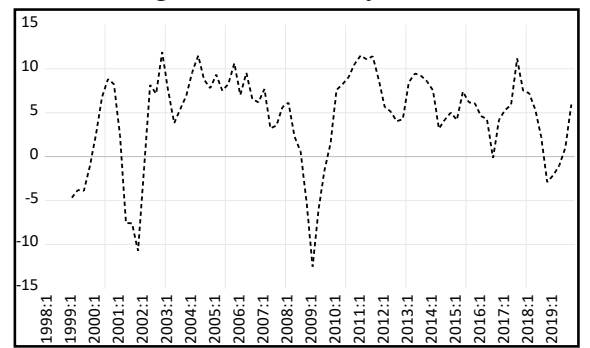

(a) GSYİHB

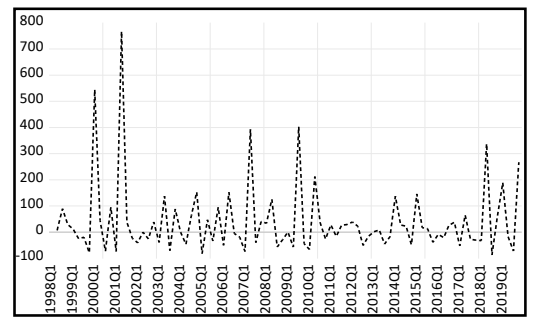

(c) WUI

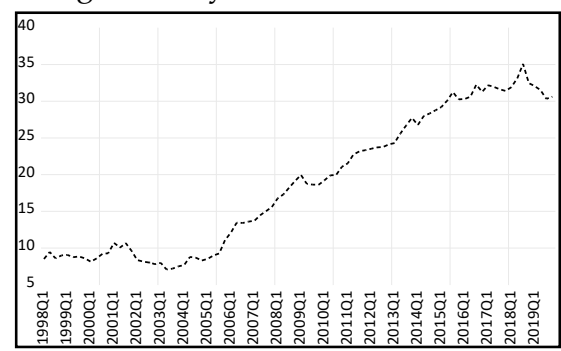

(b) KREDI

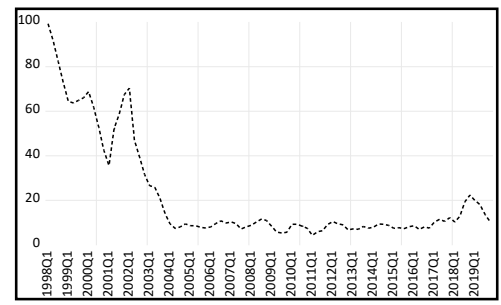

(d) ENFLASYON

Şekil 1. Türkiye'nin Ocak 1998- Aralık 2019 tarihleri arasındaki gayrisafi yurtiçi hasıladaki büyüme, finansal olmayan özel sektöre sağlanan kredilerin toplamının gayrisafi yurtiçi hasılaya oranı, belirsizlik endeksi değişimi, ve enflasyon verilerinin tarihsel değerleri. 


\section{Örneklem}

Çalışmamızda Türkiye için Ocak 1998 ve Aralık 2019 arası çeyrek periyotlardan oluşan zaman serisi veri seti kullanılmıştır. Ekonomik büyümeyi ölçmek için, literatürü takip ederek gayrisafi yurtiçi hasıla büyüme oranı (GSYİHB) kullanılmıştır (bkz. King ve Levine, 1993a, b; Calderon ve Liu, 2003, s.321). Finansal kalkınma göstergesi olarak da, yine literatürde sıkça kullanılan bankalarca finansal olmayan sektörlere verilen toplam özel kredilerin gayrisafi yurtiçi hasılaya oranı değişkeni (KREDİ) kullanılmıştır. Bu değişken, bankaların aracilık aktivitelerini gösterirken, finans araclarının hizmet kalitesi hakkında fazla bilgi vermemektedir. Fakat literatürde finansal kurumların kalitesiyle açıkça ilgilenen daha iyi bir finansal piyasa göstergesi bulunmadığ için bu değişken tercih edilmiştir (Leninsk, 2001). Belirsizlik verisi olarak, Ahir vd.'nin (2018) oluşturduğu ülke bazında dünya belirsizlik endeksinin değişim oranı (WUI) kullanılmıştır. 1996 senesinden itibaren her çeyrekte 143 ülke için oluşturulan bu endeks, üç ayda bir çıan "Economist Intelligence Unit" ülke raporlarında "belirsizlik" kelimesinin sıklığı kullanılarak oluşturulmuştur. Çalışmamızda ayrıca, ENTFK (KREDI*WUI) ve ENTEB (GSYIHHB*WUI) etkileşim terimleri de kullanılmıştır. Kontrol değişkeni olarak ise modele, literatürü takriben enflasyon oranı (ENFLASYON) eklenmiştir. KREDİ dışındaki bütün veriler OECD veri bankasından ${ }^{1}$ elde edilirken, KREDİ verisine Federal Reserve Bank of St. Louis Economic Data (FRED) ${ }^{2}$ web sitesinden ulaşılmıştır.

Değişkenlere ait tanımlayıcı istatistikler, Tablo 1'de gösterilmiştir. Değişkenlerin grafikleri ise Şekil 1'de sunulmuştur. Buna göre, hiçbir değişken dönemsellik göstermemektedir. KREDİ değişkeninde yukarı yönlü, Enflasyonda ise aşağı yönlü eğilim dikkat çekmektedir.

\section{Bulgular}

Yukarıda da belirtildiği üzere, ARDL metodolojisinin uygulanabilmesi için, serilerin ikinci derecede durağanlıktan daha az bir durağanlığa sahip olması gerekmektedir (Peseran vd., 2001, s. 289-300). Bu nedenle, ilgili değişkenlerin

\footnotetext{
${ }^{1}$ OECD (2010)

${ }^{2}$ Retrieved from FRED, Federal Reserve Bank of St. Louis; https://fred.stlouisfed.org/series/.
} 
durağanlık derecelerini bulmak amacıyla, literatürde sıkça kullanılan Augmented Dickey Fuller (ADF) (1979) ve Im- Peseran- Shin (IPS) (2003) birim kök testleri uygulanmıştır. Sonuçlar Tablo 2'de verilmiştir. Buna göre, KREDİ dışında bütün değişkenler düzeyde durağanken, KREDİ birinci derecede durağandır. ARDL modelinden yararlanmak için bir engel bulunmamaktadır.

Tablo 2. Birimkök test sonuçları

\begin{tabular}{lllll}
\hline & IPS & & ADF & \\
\hline & İstatistik & Gecikme & İstatistik & Gecikme \\
\hline Panel A: Düzey & & & & \\
\hline GSYİHB & $-2.810^{*}$ & 4 & $-3.288^{* *}$ & 4 \\
KREDİ & -0.117 & 0 & -0.590 & 0 \\
WUI & $-11.646^{* * *}$ & 0 & $-8.747^{* * *}$ & 1 \\
ENTFK & $-9.241^{* * *}$ & 1 & $-8.712^{* * *}$ & 1 \\
ENTEB & $-9.350^{* * *}$ & 0 & $-11.247^{* * *}$ & 0 \\
ENFLASYON & $-2.709^{*}$ & 5 & $-6.971^{* * *}$ & 8 \\
\hline Panel B: Ilk fark & & & & \\
\hline GSYİHB & $-8.357^{* * *}$ & 3 & $-8.065^{* * *}$ & 3 \\
KREDI & $-8.893^{* * *}$ & 0 & $-7.794^{* * *}$ & 0 \\
WUI & $-8.604^{* * *}$ & 4 & $-7.224^{* * *}$ & 4 \\
ENTFK & $-11.605^{* * *}$ & 2 & $-11.327^{* * *}$ & 2 \\
ENTEB & $-9.556^{* * *}$ & 2 & $-10.102^{* * *}$ & 2 \\
ENFLASYON & $-3.758^{* * *}$ & 4 & $-3.214^{* *}$ & 4 \\
\hline Not: Tablo 2 & & & & \\
\hline
\end{tabular}

Not: Tablo 2' de kullanılan değişkenlerin birim kök testi sonuçları sunulmuştur. GSYİHB, KREDİ, WUI, ENTFK, ENTEB, ENFLASYON sırasıyla gayrisafi yurtiçi hasıladaki büyüme, finansal olmayan özel sektöre sağlanan kredilerin toplamının gayrisafi yurtiçi hasılaya oranı, belirsizlik endeksi değişimi, finansal kalkınma etkileşim terimi, ekonomik büyüme etkileşim terimi, ve enflasyonu belirtmektedir. IPS, Im- Peseran- Shin testini, ADF ise Augmented-Dickey Fuller testini ifade etmektedir. ${ }^{* * *},{ }^{* * *}$ sirasılyla yüzde 1, yüzde 5, ve yüzde 10 seviyesinde anlamlılı̆̆ göstermektedir.

Tablo 3. Sınır testi sonuçları

\begin{tabular}{|c|c|}
\hline Eşbütünleşme Hipotezleri & F İst.. \\
\hline F(GSYIHBBt/KREDİ,WUIt,ENTFKt, ENFLASYON ${ }_{\mathrm{t}}$ ) & $4.325^{* * *}$ \\
\hline F(KREDİ/GSYIHBBt,WUIt,ENTEBt, ENFLASYON $\left.{ }_{t}\right)$ & $5.237^{* * *}$ \\
\hline
\end{tabular}

Not: Tablo 3'de iki model için sınır testi sonuçları sunulmuştur. GSYİHB, KREDİ, WUI, ENTFK, ENTEB, ENFLASYON sırasıyla gayrisafi yurtiçi hasıladaki büyüme, finansal olmayan özel sektöre sağlanan kredilerin toplamının gayrisafi yurtiçi hasılaya oranı, belirsizlik endeksi değişimi, finansal kalkınma etkileşim terimi, ekonomik büyüme etkileşim terimi, ve enflasyonu belirtmektedir. ${ }_{,}^{* * *},{ }^{* * *}$ sirasiyla yüzde 1 , yüzde 5 , ve yüzde 10 seviyesinde anlamlılığı göstermektedir. 
ARDL modelinin ilk aşaması olan uzun dönem eşbütünleşmenin varlığı, sınır testi yaklaşımıyla belirlenmiştir. Sonuçlar Tablo 3'de sunulmuştur. F istatistiği, her iki model için de kritik üst sınırdan büyük olduğu için, $\mathrm{H}_{0}$ reddedilmiştir (Peseran vd., 2001). Bu nedenle, ekonomik büyümenin bağımlı değişken olduğu modelde de, finansal kalkınmanın bağımlı değişken olduğu modelde de ilgili değişkenler arasında eşbütünleşme ilişkisi olduğu saptanmıştır. Dolayısıyla, ekonomik büyüme, finansal kalkınma, ülke belirsizliği, enflasyon ve etkileşim terimleri arasında uzun dönemli bir ilişkinin varlığ1 söz konusudur.

Uzun dönemli eşbütünşleşmenin varlığı sınır testi yaklaşımıyla tespit edildikten sonra, ARDL metodunun ikinci aşaması olan ilk adımda belirlenen uzun dönemli ilişkilerin katsayıları, üçüncü ve dördüncü denklemler test edilerek tahmin edilmiştir. Ekonomik büyümenin bağımlı değişken olduğu denklem 3'ün analiz sonuçları, Tablo 4'ün A Panelinde sunulmuştur. Bu sonuçlara göre, uzun dönemde, ekonomik büyümeyi kendi gecikmesi ve enflasyon değişkeni dışında anlamlı olarak etkileyen başka bir faktör bulunamamıştır. Uzun dönemde enflasyonun artması, ekonomik büyümeyi azaltmaktadır. Bu sonuç, enflasyon ve ekonomik büyüme arasındaki negatif ilişkiye işaret eden literatürle örtüşmektedir (Fischer,1993; Barro, 1995; Grimes, 1991). Finansal kalkınmaya diğer ilgili değişkenlerin uzun dönem etkileri ise, Tablo 5'de A panel'inde gösterilmiştir. Sonuçlar, GSYİHB'nin katsayısının anlamlı ve pozitif olduğunu, dolayısıyla uzun vadede ekonomik büyümenin finansal kalkınmayı arttırdığını ortaya koymuştur. Bu sonuçlara göre, Türkiye incelenen periyot için uzun vadede, talep-takibi davranışı sergilemektedir (Patrick, 1966). Belirsizliğin ne ekonomik büyüme ne de finansal kalkınma üzerinde uzun dönemli anlamlı bir etkisi bulunamamıştır. Bu da politika yapıcılar, şirketler ve hanehalkı tarafından belirsizliğe anlık tepkiler verildiği, bu nedenle uzun dönemli etki gözlemlenemediği şeklinde yorumlanabilir. 
Tablo 4. ARDL modeli tahmin sonuçları (Bağımsız değişken: DGSYïHB)

\begin{tabular}{|c|c|c|c|c|}
\hline Bağımsız Değişken & Katsay1 & Standard Hata & t-istatistiği & Olasılık \\
\hline \multicolumn{5}{|c|}{ Panel A: ARDL Modeli Uzun Dönem Tahmin Sonuçlart-Bağımsız Deişken GSYİHB } \\
\hline $\mathrm{C}$ & 5.1822 & 1.3967 & 3.7104 & 0.0005 \\
\hline GSYİHB $\mathrm{t}-1$ & -0.3459 & 0.0954 & -3.6265 & 0.0006 \\
\hline KREDİ $\dot{\mathrm{t}}_{-1}$ & -0.0609 & 0.0454 & -1.3406 & 0.1852 \\
\hline WUIt-1 & 0.0106 & 0.0130 & 0.8157 & 0.4180 \\
\hline ENTFK $_{\mathrm{t}-1}$ & -0.0007 & 0.0007 & -1.0578 & 0.2945 \\
\hline ENFLASYON $\mathrm{t}_{-1}$ & -0.0782 & 0.0280 & -2.7961 & 0.0070 \\
\hline \multicolumn{5}{|c|}{ Panel B: ARDL Hata Düzeltme Modeli Tahmin Sonuçlart-Bağımsız Deişken GSYİHB } \\
\hline DGSYİHBt-1 & 0.3655 & 0.1170 & 3.1250 & 0.0028 \\
\hline DGSYİHBt-2 & 0.1078 & 0.1207 & 0.8934 & 0.3753 \\
\hline DGSYİHBt-3 & 0.2612 & 0.1134 & 2.3029 & 0.0248 \\
\hline DKREDİ & -1.0062 & 0.4727 & -2.1286 & 0.0375 \\
\hline DKREDİं 1 & -0.4011 & 0.4449 & -0.9016 & 0.3709 \\
\hline DKREDİं-2 & -0.2727 & 0.4482 & -0.6085 & 0.5452 \\
\hline DKREDİं-3 & -1.0025 & 0.4432 & -2.2619 & 0.0274 \\
\hline DWUIt- & -0.0022 & 0.0057 & -0.3835 & 0.7027 \\
\hline DWUIt $-1_{1}$ & -0.0115 & 0.0057 & -2.0345 & 0.0464 \\
\hline DENTFK $_{t}$ & 0.0000 & 0.0003 & 0.1407 & 0.8886 \\
\hline DENTFK $_{\mathrm{t}-1}$ & 0.0008 & 0.0003 & 2.3817 & 0.0205 \\
\hline DENFLASYON $_{t}$ & -0.2191 & 0.1026 & -2.1346 & 0.0370 \\
\hline DENFLASYONt-1 & 0.3026 & 0.0920 & 3.2904 & 0.0017 \\
\hline DENFLASYONt-2 & -0.1172 & 0.0982 & -1.1928 & 0.2377 \\
\hline DENFLASYONt-3 & 0.2435 & 0.0881 & 2.7643 & 0.0076 \\
\hline ECT(-1) & -0.3459 & 0.0652 & -5.3057 & 0.0000 \\
\hline Düzeltilmiş $\mathrm{R}^{2}$ & 0.4643 & & & \\
\hline
\end{tabular}

Not: Tablo 4' de Panel A'da ARDL modeli uzun dönem tahmin sonuçları verilirken, Panel B'de ARDL hata düzeltme modeli tahmin sonuçları sunulmuştur. GSYİHB, KREDİ, WUI, ENTFK, ENFLASYON sırasıyla gayrisafi yurtiçi hasıladaki büyüme, finansal olmayan özel sektöre sağlanan kredilerin toplamının gayrisafi yurtiçi hasılaya oranı, belirsizlik endeksi, finansal kalkınma etkileşim terimi, ve enflasyonu belirtmektedir. C sabit katsayısıdır. Hata düzeltme terimi ECT ile gösterilmiştir.

Çalışmamızın son aşamasında, ilgili değişkenler arasındaki kısa dönem ilişkisi, ARDL Hata Düzeltme Modeli yardımıyla tahmin edilmiştir. Değişkenlerin ekonomik büyüme üzerindeki kısa dönem etkisi, Tablo 4-Panel B'de sunulmuştur. Sonuçlar uzun dönemden bir hayli farklıdır. Öncelikle, belirsizliğin ekonomik büyümeyi anlamlı ve negatif olarak etkilediği belirlenmiştir. Bu sonuç, istikrarsızlığın yatırımları ve tasarrufları olumsuz yönde etkileyerek ekonomik büyümeyi azaltacağını iddia eden literatürle örtüşmektedir (Barro, 1991; Mauro, 1995; Alesina ve Perotti, 1996; Jong-a-Pin, 2009). Bu çalışmalardan farklı olarak, finansal kalkınma ve belirsizliğin etkileşim terimi olan ENTFK'nın kısa dönem katsayısı da anlamlı ve pozitif bulunmuştur. 
Buna göre, belirsizliğin ekonomik büyüme üzerinde neden olduğu negatif etki, finansal kalkınmanın artmasıyla azalmaktadır. Bu sonuç, 50 ülke için panel veri setini kullanarak finansal gelişmenin, belirsizliğin ekonomik çıktı üzerindeki olumsuz etkisini azalttı̆̆ını gösteren Karaman ve Karaman (2019)'ın çkarımlarının kısa vadede Türkiye için de desteklendiğini göstermektedir. Bunlara ek olarak, finansal kalkınmanın ekonomik büyümeyi, uzun vadenin aksine, kısa dönemde etkilediği bulunmuştur.

Tablo 5. ARDL modeli tahmin sonuçlan (Bă̆ımsız değişken: DKREDİ)

\begin{tabular}{|c|c|c|c|c|}
\hline Bağımsız Değişken & Katsay1 & Standard Hata & t-istatistiği & Olasilik \\
\hline \multicolumn{5}{|c|}{ Panel A: ARDL Modeli Uzun Dönem Tahmin Sonuçlart- Bağımsız Deişken KREDİ } \\
\hline $\mathrm{C}$ & 0.4248 & 0.3292 & 1.2902 & 0.2011 \\
\hline KREDİंt & -0.0119 & 0.0105 & -1.1392 & 0.2583 \\
\hline GSYİHB $\mathrm{t}_{\mathrm{t}-1}$ & 0.0442 & 0.0196 & 2.2481 & 0.0276 \\
\hline WUIt-1 & 0.0012 & 0.0010 & 1.1404 & 0.2579 \\
\hline 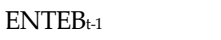 & 0.0001 & 0.0002 & 0.6780 & 0.4999 \\
\hline ENFLASYON $\mathrm{t}-1$ & -0.0099 & 0.0059 & -1.6880 & 0.0957 \\
\hline \multicolumn{5}{|c|}{ Panel B: ARDL Hata Düzeltme Modeli Tahmin Sonuçlart-Bağımsız Deişken KREDİ } \\
\hline DGSYİHB $_{t}$ & -0.0151 & 0.0284 & -0.5306 & 0.5973 \\
\hline DWUIt- & -0.0002 & 0.0006 & -0.2505 & 0.8029 \\
\hline DENTEB $_{\mathrm{t}}$ & 0.0001 & 0.0001 & 0.9510 & 0.3448 \\
\hline DENFLASYON $_{\mathrm{t}}$ & -0.0031 & 0.0229 & -0.1356 & 0.8925 \\
\hline ECT(-1) & -0.0113 & 0.0652 & -5.3057 & 0.0000 \\
\hline
\end{tabular}

Not: Tablo 4' de Panel A'da ARDL modeli uzun dönem tahmin sonuçları verilirken, Panel B'de ARDL hata düzeltme modeli tahmin sonuçları sunulmuştur. GSYİHB, KREDİ, WUI, ENTFK, ENTEB, ENFLASYON sırasıyla gayrisafi yurtiçi hasıladaki büyüme, finansal olmayan özel sektöre sağlanan kredilerin toplamının gayrisafi yurtiçi hasılaya oranı, belirsizlik endeksi, ekonomik büyüme etkileşim terimi, ve enflasyonu belirtmektedir. C sabit katsayısıdır. Hata düzeltme terimi ECT ile gösterilmiştir.

Değişkenlerin finansal kalkınmaya kısa dönem etkileri ise Tablo 5- Panel B'de gösterilmiştir. Sonuçlar, modele dahil edilen hiçbir değişkenin, kısa vadede finansal kalkınmaya anlamlı bir etkisi olmadığı yönündedir. Ekonomik büyüme dahi, uzun dönemde finansal kalkınmayı arttırırken, kısa dönemde anlamlı olarak etkilememektedir. Bir diğer deyişle, Türkiye incelenen zaman dilimi için kısa vadede, arz-liderliği davranışı sergilemektedir (Patrick, 1966). Finansal kalkınmanın kısa dönemde ekonomik büyümeyi etkileyip uzun vadede etkilememesi, finansal sistemin uzun vadede üretken yatırımları belirlemekte ve fonlamakta sıkıntı yaşıyor olabileceği şeklinde de yorumlanabilir. 
Her iki kısa dönem model için de, hata terimi katsayısı beklenildiği üzere anlamlı ve negatiftir. Dolayısıyla, kısa vadede oluşan dengeden sapmalar, uzun vadede dengeye yaklaşmaktadır. Buna göre, ekonomik büyümenin bağımlı olduğu model için, kısa dönem şoklarının neden olduğu uzun vade dengesinde oluşacak sapmalar bir dönemin ardından \%34.59 giderilebilecekken, bu rakam finansal kalkınmanın bağımlı değişken olduğu model için çok daha yavaş ve \%1.13 civarındadır (bkz. Akel ve Gazel, 2014, s. 37).

\section{Tartışma ve Sonuç}

Ekonomik büyüme ve finansal kalkınma arasındaki ilişki, çok uzun süredir üzerinde tartışılan bir konudur. Belirsizliğin makroekonomik değişkenler üzerindeki etkisi ise son yıllarda yoğun tartışmaların odağı olmuştur. Çalışmamız, ekonomik büyüme ve finansal gelişmişlik düzeyinin, belirsizliğin etkileri üzerinde bir fark yaratıp yaratmadığını araştırarak, bu iki literatür arasindaki boşluğu doldurmayı hedeflemiştir. Örneklem olarak, Türkiye için Ocak 1998-Aralık 2019 arasındaki dönem incelenmiştir. Uzun dönem eşbütünleşmenin varlı̆̆ı için sınır testi yaklaşımından yararlanılırken, uzun dönem ve kısa dönem için ilgili değişkenlerin etkisi, gecikmesi dağıtılmış otoregresif model (ARDL) yöntemiyle tahmin edilmiştir.

Ampirik analizlerimizin bulgularına göre, belirsizliğin ekonomik büyüme üzerinde uzun vadeli bir etkisi bulunmazken, belirsizliğin artması kısa vadede ekonomik büyümeyi azaltmaktadır. Ancak bu olumsuz etki, finansal kalkınma arttıkça düşmektedir. Bu sonuç, Leninsk (2001) ve Karaman ve Karaman (2019)'un bulgularını destekler niteliktedir. İyi gelişmiş bir finansal sistem, riskleri daha etkin bir biçimde yöneterek, belirsizliğin olumsuz etkisini törpülemektedir. Zayıf bir finansal sistemin varlığında ise, belirsizlik ekonomik büyümeye çok daha fazla zarar vermektedir (Leninsk, 2001). Belirsizliğin ekonomik aktiviteyi finansal sürtünmeler yoluyla bastırdığı koşullarda, az finansal gelişmişlik, sürtünmeleri daha da kötüleştirerek negatif etkiyi arttırmaktadır (Karaman ve Karaman, 2019). Öte yandan çalışmamızda, belirsizliğin finansal kalkınma üzerinde kısa veya uzun vadede anlamlı bir etkisi saptanamamıştır. Aynı zamanda, ekonomik büyümenin de belirsizliğin finansal kalkınma üzerindeki etkisinde bir değişikliğe yol açmadığı gözlemlenmiştir. Bu sonuç, ekonomik politika belirsizliğindeki artısıın kredi kullanılabilirliğini 
azalttığını ortaya koyan Cağlayan ve Xu'nun (2019) bulgularıyla örtüşmemektedir. Son olarak, ekonomik büyüme ve finansal kalkınma arasındaki ilişkiyi incelediğimizde, Türkiye'nin incelenen dönem için uzun vadede, taleptakibi davranışı gösterdiği bulunurken, uzun dönemde arz-liderliği davranışı sergilediği gözlemlenmiştir. Finansal kalkınmanın kısa dönemde ekonomik büyüme üzerinde etkisi varken, uzun dönemde anlamlı bir etkinin gözlemlenememesi, finansal sistemin uzun vadede üretken yatırımları belirlemekte ve fonlamakta sorun yaşıyor olabileceği ve bunun finansal sistemin kalitesiyle ilgili bir problemin varlığına işaret ediyor olabileceği şeklinde yorumlanmıştır.

Sonuç olarak çalışmamız, özellikle gelişmekte olan ülkelerdeki politika yapıcılar için önemli çıktılar sunmaktadır. Finansal sistemin görece daha az gelişmiş olduğu bu ülkelerde, belirsizliğin ekonomik büyüme üzerinde çok daha yıkıcı etkileri olacaktır. Politika yapıcılar tarafından, finansal sektörün gelişmişliğini ve kalitesini arrtırmaya yönelik atılacak adımlar ise, belirsizliğin çıktı üzerindeki olumsuz etkilerini azaltmak adına büyük önem arz etmektedir. Bu da finansal sektörün, özellikle gelişmekte olan ülkeler için önemini bir kez daha vurgulamaktadır. 


\section{EXTENDED ABSTRACT}

\section{Impact of Uncertainty Depending on the Economic Growth and Financial Development Level: The Case of Turkey}

Ecenur Uğurlu Yıldırım*

Social Sciences University of Ankara

The relationship between economic growth and financial development has been at the center of discussions for a long time. The impact of the uncertainty of a country on macroeconomic indicators has also become another subject of interest in recent years. In this study, it is aimed to contribute to the link between these two literatures by empirically examining whether the level of economic growth and financial development makes a difference on the effect of country uncertainty for Turkey.

The contribution of this article to the aforementioned literature can be grouped under two main headings. First, it is the first study that empirically shows whether the impact of uncertainty on economic growth and financial development has changed with economic growth and level of financial development for Turkey. Our findings show that the negative impact of uncertainty on economic growth for the short term decreases as financial development increases. Another contribution we provide to the literature is to present the long-term and short-term effects of uncertainty on financial development in Turkey by ARDL method. According to our results, country uncertainty has no effect on financial development in neither the long nor short run.

Time series data for the period between January 1998 and December 2019 on a quarterly basis for Turkey are used as a sample. Following the literature, in order to measure economic growth, the gross domestic product growth rate (GDPR) is used (see King and Levine, 1993a, b; Calderon and Liu, 2003, p.321). As a financial development indicator, total private loans given to the non-financial sectors by banks to gross domestic product ratio (CREDIT) is employed. As a uncertainty variable, change in the World Uncertainty Index (WUI) constructed by Ahir et al. (2018) is employed. Moreover, the interaction terms ENTFK (CREDIT ${ }^{*}$ WUI) and ENTEB (GDP * WUI) are also included to the model. As a control variable, the inflation rate (INFLATION), is 
employed. While all data except CREDIT is obtained from the OECD data bank, CREDIT data is gathered from the Federal Reserve Bank of St. Retrieved from the Louis Economic Data (FRED) website.

The existence of long-term cointegration, which is the first step of the ARDL model, is determined by the Bounding test approach. Results have shown that there is a cointegration relationship between the variables in interest for the model in which economic growth is the dependent variable and for the model in which financial development is the dependent variable. Therefore, it is concluded that there is a long-term relationship between the economic growth, financial development, country uncertainty, inflation and interaction terms for Turkey.

After determining the existence of long-run cointegration between variables with the Bounding test approach, the long and short-run relationship between variables are examined by employing Autoregressive Distributed Lag (ARDL) model. According to the findings of the empirical analysis, uncertainty does not have a long-run effect on economic growth, while increasing uncertainty decreases economic growth in the short run. However, this negative effect decreases as financial development increases. This result supports the findings of Leninsk (2001) and Karaman and Karaman (2019) that state a well-developed financial system mitigates the negative impact of uncertainty by managing risks more effectively. In the presence of a weak financial system, uncertainty causes more damage to economic growth (Leninsk, 2001). Under conditions where uncertainty suppresses economic activity through financial friction, lower financial development increases the negative effect by worsening friction (Karaman \& Karaman, 2019). On the other hand, in this study, no significant effect of uncertainty on financial development in the short nor long-run is detected. At the same time, it is observed that economic growth does not change the impact of uncertainty on financial development. This result does not coincide with the findings of Cağlayan and $\mathrm{Xu}$ (2019), which revealed that the increase in economic policy uncertainty decreases loan availability. Finally, when we examine the relationship between economic growth and financial development, it is observed that Turkey performs demand-following behavior in the long-run, while it exhibits a supplyleading behavior in the short-run for the period examined. While financial development has an effect on economic growth in the short-run, the inability 
to observe a significant effect in the long-run indicates that the financial system may be having trouble identifying and funding productive investments in the long term, and this may indicate the existence of a problem with the quality of financial system provision.

As a result, our study provides important outcomes for policy makers, especially in developing countries. In these countries where the financial system is relatively less developed, uncertainty will have even more devastating effects on economic growth. The steps to be taken by policy makers to increase the development and quality of the financial sector are of great importance in order to reduce the negative effects of uncertainty on output. This once again emphasizes the importance of the financial sector, especially for developing countries.

\section{Kaynakça / References}

Ahir, H., Bloom, N., ve Furceri, D. (2018). The world uncertainty index. Mimeo, http://www.policyuncertainty.com/media/WUI mimeo 10 29.pdf. Sitesinden alınd.

Aizenman, J. ve Marion, N.P. (1993). Macroeconomic uncertainty and private investment. Economic Letters, 41, 207-210.

Akel, V., ve Gazel, S. (2014). Döviz kurları ile BIST sanayi endeksi arasındaki eşbütünlelme ilişkisi: Bir ARDL sınır testi yaklaşımı. Erciyes Üniversitesi İktisadi ve İdari Bilimler Fakültesi Dergisi, 44, 23-41.

Alesina, A. ve Perotti, R. (1996). Income distribution, political instability, and investment. European Economic Review, 40, 1203- 1228.

Barro, R.J. (1991). Economic growth in a cross-section of countries. Quarterly Journal of Economics, 106, 407-443.

Barro, R.J. (1995). Inflation and economic growth. Bank of England Quarterly Bulletin, 35, 407-443.

Bui, D. T. (2018). Fiscal policy and national saving in emerging Asia: Challenge or opportunity? Eurasian Economic Review, 1-18.

Caglayan, M., ve Xu, B. (2019). Economic policy uncertainty effects on credit and stability of financial institutions. Bulletin of Economic Research, 71, 342-347.

Calderon C. A. V., ve Liu, L. (2003). The direction of causality between financial development and economic growth. Journal of Development Economics, 72, 321-334.

Chi, Q., ve Li, W. (2017). Economic policy uncertainty, credit risks and banks' lending decisions: Evidence from Chinese commercial banks. China Journal of Accounting Research, 10, 33-50. 
Dickey, D.A., ve Fuller, W.A. (1979). Distribution of the estimators for autoregressive time series with a unit root. Journal of the American Statistical Society, 75, 427-431.

Dixit, A.K. ve Pindyck, R. S. (1994). Investment under Uncertainty. Princeton University Press.

Fischer, S. (1993). The Role of Macroeconomic Factors in Growth. Journal of Monetary Economics, 32, 485-511.

Ghatak, S., ve Siddiki, J. (2001) The use of ARDL approach in estimating virtual exchange rates in India. Journal of Applied Statistics, 28, 573-583.

Gozgor, G., Demir, E., Belas, J., ve Yesilyurt, S. (2019). Does economic uncertainty affect domestic credits? An empirical investigation. Journal of International Financial Markets, Institutions and Money, 63.

Grimes, A. (1991). The Effects of inflation on growth: Some international evidence. Weltwirtschaftliches Archiv, 127, 631-644.

Im, K.S., Pesaran,M.H. ve Shin, Y. (2003). Testing for unit roots in heterogeneous panels. Journal of Econometrics, 115, 53-74.

Jong-a-Pin, R. (2009). On the measurement of political instability and its impact on economic growth. European Journal of Political Economy, 25, 15-29.

Karaman, K. K., ve Karaman, S. Y. (2019). How does financial development alter the impact of uncertainty? Journal of Banking and Finance, 102, 33-42.

King, R.G. ve Levine, R. (1993 a). Finance and growth: Schumpeter might be right. Quarterly Journal of Economics, 108, 717-38.

King, R.G. ve Levine, R. (1993b). Finance, entrepreneurship, and growth: Theory and evidence. Journal of Monetary Economics, 32, 513-42.

Laurenceson, J., ve Chai, J.C.H. (2003). Financial Reform and Economic Development in China. Edward Elgar, Cheltenham, UK.

Lensink, B. W. (2001). Financial development, uncertainty and economic growth. De Economist, 149, 299-312.

Lucas, R. E. Jr. (1988). On the mechanics of economic development. Journal of Monetary Economics, 22, 3-42.

Mauro, P. (1995). Corruption and growth. Quarterly Journal of Economics, 110, 681-712.

McKinnon, R. (1973). Money and capital in economic development. Brookings Institution. Washington, DC, USA

Patrick, H.T. (1966). Financial development and economic growth in underdeveloped Countries. Economic Development and Cultural Change, 14, 174-189.

Pesaran, M.H. ve Pesaran, B. (1997), Working with Microfit 4.0. Camfit Data Ltd, Cambridge. 
Pesaran, M.H., Shin, Y. ve Smith, R.J. (2001). Bounds testing approaches to the analysis of level relationships. Journal of Applied Econometrics, 16, 289-326.

Robinson, J. (1952). The generalization of the general theory. Rate of Interest and Other Essays içinde, London: Macmillan.

Sari, R., Ewig, B. T., ve Soytas, U. (2008) The Relationship between disaggregate energy consumption and industrial production in the United States: An ARDL Approach. Energy Economics, 30, 2302-2313.

Schumpeter, J.A. (1961). The theory of economic development. Leipzig: Dunker and Humblot, 1912; çeviri REDVERS OPIE. Oxford University Press.

Shaw, E. S. (1973). Financial deepening in economic development. Oxford University Press, New York

Stock, J.H., ve Watson, M.W. (2003). Introduction to econometrics. Addison Wesley, Boston.

\section{Kaynakça Bilgisi / Citation Information}

Uğurlu Yıldırım, E. (2021). Ekonomik büyüme ve finansal kalkınma seviyesine göre belirsizliğin etkisi: Türkiye örneği. OPUS-Uluslararası Toplum Araştırmaları Dergisi, 17(37), 4429-4449 DOI: 10.26466/opus.780239 